Published in final edited form as:

Ann Clin Psychiatry. 2005 ; 17(4): 205-210.

\title{
Recognizing and Treating Body Dysmorphic Disorder
}

\author{
JON E. GRANT, J.D., M.D. \\ Department of Psychiatry, University of Minnesota, Minneapolis, MN, USA
}

KATHARINE A. PHILLIPS, M.D.

Department of Bio Med Psychiatry and Human Behavior, Brown University, Providence, RI, USA

\section{Abstract}

Background-Body dysmorphic disorder (BDD) is a relatively common and often-disabling obsessive compulsive spectrum disorder that often goes unrecognized in clinical practice.

Methods-The present review examines the clinical features of BDD, its relationship to other disorders, and what is known about effective treatment.

\begin{abstract}
Results-BDD consists of a distressing and impairing preoccupation with imagined or slight defects in appearance that can focus on any body area. Insight is usually poor or absent; nearly half of patients are delusional. Typical associated behaviors include skin picking, mirror checking, excessive grooming, and camouflaging. It appears that higher doses of serotonin reuptake inhibitors and longer treatment trials than those used for many other psychiatric disorders, including depression, are often needed to effectively treat BDD. Cognitive-behavioral therapy also appears efficacious and is currently considered the psychotherapy of choice for $\mathrm{BDD}$. Core techniques are cognitive restructuring, behavioral experiments, response (ritual) prevention, and exposure.
\end{abstract}

Conclusions-Further research is needed to minimize the underrecognition of BDD and to improve proper treatment. Because of the high rates of comorbidity in patients with BDD, treatment studies need to include subjects with co-occurring disorders and thereby attempt to understand how these other disorders affect treatment response. Finally, more research needs to address the pathophysiology of BDD (for example, by incorporating imaging and genetics).

\section{Keywords}

Body dysmorphic disorder; Obsessive compulsive spectrum disorder; Skin picking; Mirror checking; Excessive grooming; Camouflaging

\section{INTRODUCTION}

Most people are dissatisfied with some aspect of their appearance. In fact, more than half of all women and nearly half of all men in the United States are dissatisfied with the way they look (1). For some people, however, they are preoccupied with imaginary defects in appearance and their concerns about appearance are excessive (2). These patients suffer from body dysmorphic disorder (BDD), a disorder characterized by significant distress, impaired functioning, social withdrawal, and repeated attempts to hide or correct the imagined defect (3).

Despite having been described around the world for more than a century (4), BDD was not included in diagnostic systems until DSM-III and ICD-10 (56). DSM-III included BDD as an

Address correspondence to Jon E. Grant, J.D., M.D., Department of Psychiatry, University of Minnesota, 2450 Riverside Avenue, Minneapolis, MN 55454, USA. E-mail: grant045@umn.edu. 
example of an atypical somatoform disorder, and DSM-III-R provided diagnostic criteria (7). Although DSM-IV allows people with delusional BDD to receive a diagnosis of both delusional disorder and BDD, ICD-10 classifies delusional BDD as a variant of delusional syndrome (2, $6)$.

$\mathrm{BDD}$ is a relatively common disorder. Although studies within the general population have found prevalence rates ranging from $0.7 \%$ to $5.3 \%$ (8-12), studies of clinical samples suggest higher rates: $8.8 \%-12 \%$ among dermatology patients (13-14); 7\% among cosmetic surgery patients (15); $14 \%-42 \%$ in patients with atypical major depression (16-18); $11-13 \%$ in patients with social anxiety (19-20); 8\%-37\% in patients with obsessive compulsive disorder (2022); and 39\% in patients with anorexia nervosa (23).

BDD affects both children and adults $(2,24)$. BDD usually starts in adolescence and appears to be about equally common in men and women or slightly more common in women (5).

\section{CLINICAL FEATURES}

Individuals with BDD are preoccupied with the idea that some aspect, or aspects, of their appearance looks abnormal. They may describe these body areas as being unattractive, deformed, disfigured, ugly, hideous, or "not right." In reality, the perceived appearance flaw is actually minimal or nonexistent; in other words, individuals with BDD look normal. Preoccupations usually involve the face or head, most often the skin, hair, or nose (e.g., acne, scarring, marks, pale or red skin, thinning hair, excessive body hair, or a large or crooked nose) (25). However, any body part can be the focus of concern, and most patients are preoccupied with numerous body areas (24). Individuals with BDD typically think about their perceived flaws in the range of three to eight hours a day, and the thoughts are usually difficult to resist or control (26). Before treatment, most individuals with this disorder have poor or absent insight; in other words, they do not recognize that the flaw they perceive is actually minimal or nonexistent and that their concern is due to a psychiatric illness (27).

Nearly all persons with BDD perform repetitive, time-consuming behaviors. These behaviors focus on examining, improving, being reassured about, or hiding the perceived defect (2829). These behaviors are often described as "compulsive" in the sense that the urge to perform them is strong and difficult to resist. They are also sometimes referred to as "safety behaviors," meaning that they are performed to prevent a feared catastrophe (e.g., camouflaging "ghostlike" skin with bronzer to prevent feared scrutiny by other people).

The most common behaviors are camouflaging (e.g., with hair, a wig, makeup, body position, sunglasses, a hat or other clothing), comparing one's appearance with that of other people, excessively checking the perceived flaw in mirrors or other reflecting surfaces (e.g., windows), excessively grooming (e.g., applying makeup or tweezing, styling, or cutting hair), and seeking reassurance that the body area looks normal or acceptable to others (25-26). The behaviors are unlimited and varied, however, and may consist of dieting, excessive exercising or weightlifting, touching or measuring the body part, tanning, buying excessive amounts of beauty products and compulsive shopping (which can lead to financial indebtedness), repeated clothes changing, seeking surgery or medical treatment, and using potentially dangerous anabolic steroids to bulk up (30).

Nearly all patients with BDD experience impairment in social and occupational/academic functioning as a result of their appearance concerns (Table 1). People with BDD also have markedly poor quality of life $(31,32)$, and approximately one quarter of patients with BDD are so distressed that they attempt suicide (24). However, the severity of BDD varies, with some people appearing to lead relatively normal lives despite the suffering and interference they experience. Of note, one recent study found that $49 \%$ of 176 broadly ascertained individuals 
with BDD had a lifetime substance use disorder, $68 \%$ of whom reported that their BDD symptoms contributed to their substance use disorder (33).

\section{CASE EXAMPLE}

The following case illustrates a fairly common presentation of BDD and the difficulties of treatment.

Jane, a 32-year-old single Hispanic female, had been obsessed since high school with her "huge" nose and "pock-marked" skin. She reported being "absolutely convinced" that she looked "deformed and atrocious." She could not be talked out of her beliefs. Additionally, she was convinced that people on the street took special notice of her "hideous" nose and skin, and that they talked about her and snickered behind her back because she was so ugly. Due to these beliefs, Jane became severely depresed. She was unable to work or even leave her home. She attempted suicide twice and was hospitalized psychiatrically after both attempts.

Although advised against it, Jane received two rhinoplasties for a nose that outwardly appeared normal. She also received a course of isotreninoin (Accutane). These treatments left Jane even more obsessed with her appearance and feeling more depressed because her "last hopes" hadn't cured her perceived ugliness. Jane underwent psychodynamic psychotherapy without any benefit. In addition, she had trials of several medications (several antipsychotics and low doses of antidepressants), which failed to improve her symptoms. Only after a trial of escitalopram $(30 \mathrm{mg} / \mathrm{d})$ did Jane report improvement in her BDD symptoms. In fact, while Jane continued the medication, her improvement was sustained. After stopping the medication, however, Jane's symptoms recurred.

\section{ETIOLOGICAL THEORIES}

Although the etiology of BDD is most likely multifactorial (biological, psychological, sociocultural), one possible reason for the fact that Jane improved with escitalopram is that serotonin dysregulation is associated with BDD (24). BDD symptoms have been exacerbated after tryptophan depletion and have had their onset after abuse of ciproheptadine, a serotonin antagonist (34-35). Neuropyschological and brain imaging studies have also suggested that there may be impairment of the frontal-striatal and temporo-parietal-occupital circuits which process facial images and emotional information (36-40).

\section{DIAGNOSING BDD}

Numerous studies have found that BDD usually goes unrecognized in clinical settings, probably because clinicians don't screen for it and patients are too ashamed of their symptoms to spontaneously reveal them (41). However, diagnosing BDD is usually straightforward and can be done by asking patients if they are unhappy with how they look or if they worry a lot about their appearance. An affirmative answer can be followed up with questions determining the degree of distress that these concerns cause and whether they cause functional impairment. DSM-IV criteria are met when the patient reports being preoccupied with a nonexistent or minimal appearance flaw that causes clinically significant distress or impairs functioning (2). It must also be ascertained that the appearance concerns are not better accounted for by an eating disorder. Simple self-report and clinician-administered screening and diagnostic measures are available (24). It is especially important to screen for BDD in patients who present with some of the disorder's clues-for example, the behaviors described above, ideas or delusions of reference, or being housebound. 


\section{RELATIONSHIP TO OTHER MENTAL ILLNESSES}

Although BDD is classified as a somatoform disorder in DSM-IV, it has many similarities to OCD—most notably, the presence of prominent obsessions and repetitive compulsive behaviors (42). However, there appear to be differences between these disorders; for example, BDD patients are less likely to be married, have poorer insight, and are more likely to think about suicide or make a suicide attempt due to their disorder (43). They also have higher lifetime rates of major depression and social phobia than individuals with OCD (42). In addition, BDD appears more often characterized by shame, embarrassment, low self-esteem, and rejection sensitivity—features that it shares with social phobia.

BDD has also been postulated to be related to depression (24). BDD and depression often cooccur, and both disorders are characterized by low self-esteem, rejection sensitivity, and feelings of unworthiness. However, unlike depression, a core feature of BDD is prominent obsessional preoccupations and repetitive compulsive behaviors. Many depressed patients focus less on their appearance, even neglecting it, rather than overfocusing on it. In addition, onset of BDD usually precedes that of major depression, suggesting that BDD is not simply a symptom of depression. Perhaps most important, BDD appears to respond to serotoninreuptake inhibitors (SRIs) but not non-SRI antidepressants, which is an important difference between BDD and depression that has clinical implications. Another apparent difference is that BDD does not appear to respond to ECT, although data on this topic are very limited.

BDD and eating disorders share disturbed body image and a preoccupation with perceived appearance flaws (44-45). The behaviors performed by some individuals with BDD are similar to behaviors characteristic of eating disorders, such as dieting, excessive exercise, body measuring, and mirror checking. However, patients with eating disorders tend to dislike their weight and overall body size, whereas those with BDD tend to dislike more specific body parts. Furthermore, while $90 \%$ of patients with anorexia are female, this appears to be the case for only $50 \%-70 \%$ of patients with BDD $(23,44)$. The two disorders also have somewhat different comorbidity patterns. In a controlled family study of OCD, BDD was more common in firstdegree relatives of OCD probands than control probands, whereas the eating disorders were not; this finding suggests that BDD but not the eating disorders can be considered part of a familial OCD spectrum. Importantly, BDD and anorexia seem to respond differently to treatment. Unlike patients with anorexia, a majority of patients with BDD improve with SRIs. And unlike bulimia, BDD appears to respond preferentially to SRIs, whereas bulimia responds to a variety of antidepressant agents. Nonetheless, in some cases BDD does overlap with eating disorders (in particular, eating disorder NOS), as both disorders may be characterized by excessive concern with weight and being too fat, as well as behaviors such as excessive exercise and dieting. Additional research is needed to clarify BDD's relationship to other "near neighbor" disorders, such as eating disorders, OCD, social phobia, and depression.

\section{TREATMENT}

Many people suffering from BDD seek and receive surgical and nonpsychiatric medical treatments (e.g., dermatologic, dental) for their perceived appearance flaws. Available data suggest that such treatments are usually ineffective and that appearance concerns usually persist unchanged (30). This makes sense, since BDD involves an obsessional body image disturbance that is not reality based; changing a physical feature would not be expected to diminish the disorder's core pathology.

\section{Pharmacotherapy}

Because no medication is currently approved by the Food and Drug Administration (FDA) for treating BDD, patients should be informed of "off-label" use of medications for this disorder, 
as well as the empirical basis for considering medication treatment (Table 2). Clinical care necessitates perseverance and patience on the part of both patient and clinician. Although treatment studies of BDD are still limited, these studies are very consistent in finding that SRIs are often efficacious and in fact appear more efficacious than other medications, including nonSRI antidepressants (46). Response to medication usually improves functioning and decreases appearance-related preoccupations, distress, and behaviors. Treatment response often requires 10-12 weeks and use of relatively high SRI doses. Long-term treatment is often needed, and SRI efficacy for BDD appears to usually be sustained over time, although data are limited. Although SRIs appear to be efficacious, future research needs to examine whether different classes of medications (for example, anticonvulsants, stimulants, and atypical antipsychotics) (47-48) may also be beneficial.

\section{Psychotherapy}

Cognitive-behavioral therapy (CBT) is another promising approach for BDD (49). Studies have found that BDD often significantly improves when the following approaches are used: cognitive restructuring (e.g., developing more accurate and helpful beliefs about appearance), exposure (e.g., exposing the perceived defect in social situations and preventing avoidance behaviors), response prevention (stopping compulsive behaviors, such as mirror checking), and behavioral experiments (empirically testing hypotheses, i.e., dysfunctional thoughts and beliefs). Additional components, such as mirror retraining and mindfulness, may also be used. CBT has demonstrated effectiveness in treating BDD in both individual and group formats (50-53).

No studies have examined the relative efficacy of medication versus CBT, or their combination, for BDD. However, clinical experience suggests that some patients respond well to either an SRI or CBT alone, whereas others benefit from treatment with both types of treatment.

\section{CONCLUSION}

BDD causes significant distress and impairment in functioning, and it is associated with an unusually poor quality of life. Because this disorder appears relatively common, it is important to screen for BDD in clinical settings. Research on the treatment of BDD is in an early stage, so our understanding of the most effective treatments is still incomplete. SRIs, however, appear efficacious, particularly when used at relatively high doses. In addition, CBT, using a combination of cognitive and behavioral techniques, may also be beneficial.

Future research needs to address clinical strategies to minimize the underrecognition of BDD and to improve proper treatment. Because of the high rates of comorbidity in patients with $\mathrm{BDD}$, treatment studies need to include subjects with co-occurring disorders and thereby attempt to understand how these other disorders affect treatment response. Finally, more research needs to address the pathophysiology of BDD (for example, by incorporating imaging and genetics). As with any disorder, understanding etiology should allow for more effective treatments.

\section{References}

1. Pope, HG.; Phillips, KA.; Olivardia, R. The Adonis Complex: How to Identify, Treat, and Prevent Body Obsession in Men and Boys. New York: The Free Press; 2002.

2. American Psychiatric Association Committee on Nomenclature and Statistics. Diagnostic and Statistical Manual of Mental Disorders. 4th Ed. Washington, D.C: American Psychiatric Association; 2000. Text Revision

3. Phillips KA. Body dysmorphic disorder: The distress of imagined ugliness. Am J Psychiatry 1991;148:1138-1149. [PubMed: 1882990] 
4. Morselli E. Sulla dismorfofobia e sulla tafefobia. Boll Acad Sci Med (Genova) 1886;6:100-119.

5. American Psychiatric Association. Diagnostic and Statistical Manual of Mental Disorders. 3rd Ed. American Psychiatric Association; Washington, D.C: 1980.

6. World Health Organization. International Classification of Diseases, Tenth Revision. Geneva: World Health Organization; 1993.

7. American Psychiatric Association. Diagnostic and Statistical Manual of Mental Disorders. 3rd Ed. Washington, D.C.: American Psychiatric Association; 1987. Revised

8. Sarwer DB, Cash TF, Magee L, Williams EF, Thompson JK, Roehrig M, Tantless-Dunn S, Agliata AK, Wilfley DE, Amidon AD, Anderson DA, Romanofski M. Female college students and cosmetic surgery: An investigation of experiences, attitudes, and body image. Plast Reconstr Surg 2005;115:931-938. [PubMed: 15731697]

9. Faravelli C, Salvatori S, Galassi F, Aiazzi L, Drei C, Cabras P. Epidemiology of somatoform disorders: A community survey in Florence. Soc Psychiatry Psychiatr Epidemiol 1997;32:24-29. [PubMed: 9029984]

10. Bienvenu OJ, Samuels JF, Riddle MA, Hoehn-Saric R, Liang KY, Cullen BA, Grados MA, Nestadt G. The relationship of obsessive-compulsive disorder to possible spectrum disorders: Results from a family study. Biol Psychiatry 2000;48:287-293. [PubMed: 10960159]

11. Bohne A, Keuthen NJ, Wilhelm S, Deckersbach T, Jenike MA. Prevalence of symptoms of body dysmorphic disorder and its correlates: A cross-cultural comparison. Psychosomatics 2002;43:486490. [PubMed: 12444232]

12. Cansever A, Uzun O, Donmez E, Ozsahin A. The prevalence and clinical features of body dysmorphic disorder in college students: A study in a Turkish sample. Compr Psychiatry 2003;44:60-64. [PubMed: 12524637]

13. Uzun O, Basoglu C, Akar A, Cansever A, Ozsahin A, Cetin M, Ebrinc S. Body dysmorphic disorder in patients with acne. Compr Psychiatry 2003;44:415-419. [PubMed: 14505303]

14. Phillips KA, Dufresne RG, Wilkel CS, Vittorio CC. Rate of body dysmorphic disorder in dermatology patients. J Am Acad Dermatol 2000;42:436-441. [PubMed: 10688713]

15. Sarwer DB, Wadden TA, Pertschuk MJ, Whitaker LA. Body image dissatisfaction and body dysmorphic disorder in 100 cosmetic surgery patients. Plast Reconstr Surg 1998;101:1644-1649. [PubMed: 9583501]

16. Nierenberg AA, Phillips KA, Petersen TJ, Kelley KE, Alpert JE, Worthington JJ, Tedlow JR, Rosenbaum JF, Fava M. Body dysmorphic disorder in outpatients with major depression. J Affact Disord 2002;69:141-148.

17. Phillips KA, Neirenberg AA, Brendel G, Fava M. Prevalence and clinical features of body dysmorphic disorder in atypical major depression. J Nerv Ment Dis 1996;184:125-129. [PubMed: 8596110]

18. Perugi G, Akiskal HS, Lattanzi L, Cecconi D, Mastrocinque C, Patronelli A, Vignoli S, Bemi E. The high prevalence of "soft" bipolar (II) features in atypical depression. Compr Psychiatry 1998;39:63 -71. [PubMed: 9515190]

19. Brawman-Minzer O, Lydiard RB, Phillips KA, Morton A, Czepowicz V, Emmanuel N, Villreal G, Johnson M, Ballenger JC. Body dysmorphic disorder in patients with anxiety disorders and major depression: A co-morbidity study. Am J Psychiatry 1995;152:1665-1667. [PubMed: 7485632]

20. Wilhelm S, Otto MW, Zucker BG, Pollack MH. Prevalence of body dysmorphic disorder in patients with anxiety disorders. J Anxiety Disord 1997;11:499-502. [PubMed: 9407269]

21. Pigott TA, L'Heureux F, Dubbert B, Bernstein S, Murphy DL. Obsessive compulsive disorder: Comorbid conditions. J Clin Psychiatry 1994;55:15-27. [PubMed: 7961529]

22. Simeon D, Hollander E, Stein DJ, Cohen L, Aronowitz B. Body dysmorphic disorder in the DSMIV Field Trial for obsessive compulsive disorder. Am J Psychiatry 1995;152:207-209.

23. Grant JE, Kim SW, Eckert ED. Body dysmorphic disorder in patients with anorexia nervosa: Prevalence, clinical features, and delusionality of body image. Int J Eating Disorders 2002;32:291300.

24. Phillips, KA. Understanding and Treating Body Dysmorphic Disorder. New York: Oxford University Press; 1996. The broken mirror.

25. Neziroglu F, Tobias Yaryura JA. Body dysmorphic disorder: Phenomenology and case descriptions. Behav Psychother 1993;21:27-36. 
26. Veale D, Boocock A, Gourney K, Dryden W, Shah F, Willon R, Walburn J. Body dysmorphic disorder: A survey of fifty cases. Br J Psychiatry 1996;169:196-201. [PubMed: 8871796]

27. Phillips KA, McElroy SL, Keck PE, Pope HG, Hudson JI. Body dysmorphic disorder: 30 cases of imagined ugliness. Am J Psychiatry 1993;150:302-308. [PubMed: 8422082]

28. Phillips KA, McElroy SL, Keck PE, Hudson JI, Pope HG. A comparison of delusional and nondelusional body dysmorphic disorder in 100 cases. Psychopharm Bull 1994;30:179-186.

29. Hollander E, Cohen LJ, Simeon D. Body dysmorphic disorder. Psych Ann 1993;23:359-364.

30. Phillips KA, Grant JE, Siniscalchi J, Albertini RS. Surgical and nonpsychiatric medical treatment of patients with body dysmorphic disorder. Psychosomatics 2001;42:504-510. [PubMed: 11815686]

31. Phillips KA, Menard W, Fay C, Weisberg R. Demographic characteristics, phenomenology, comorbidity, and family history in 200 individuals with BDD. Psychosomatics. In press

32. Phillips KA. Quality of life for patients with body dysmorphic disorder. J Nerv Ment Dis 2000;188:170-175. [PubMed: 10749282]

33. Grant JE, Menard W, Pagano M, Fay C, Phillips KA. Substance use disorders in individuals with body dysmorphic disorder. J Clin Psychiatry 2005;66:309-316. [PubMed: 15766296]

34. Craven JL, Rodin GM. Cyproheptadine dependence associated with an atypical somatoform disorder? Can J Psychiatry 1987;32:143-145. [PubMed: 3567821]

35. Barr LC, Goodman WK. Price LH: Acute exacerbation of body dysmorphic disorder during tryptophan depletion. Am J Psychiatry 1992;149:1406-1407. [PubMed: 1388335]

36. Deckersbach T, Savage CR, Phillips KA, Wilhelm S, Buhlmann U, Rauch SL, Baer L, Jenike MA. Characteristics of memory dysfunction in body dysmorphic disorder. J Int Neuropsychol Soc 2000;6:673-681. [PubMed: 11011514]

37. Buhlmann U, McNally RJ, Wilhelm S, Florin I. Selective processing of emotional information in body dysmorphic disorder. J Anxiety Disord 2002;16:289-298. [PubMed: 12214814]

38. Buhlmann U, McNally RJ, Etcoff NL, Tuschen-Caffier B, Wilhelm S. Emotion recognition deficits in body dysmorphic disorder. J Psychiatr Res 2004;38:201-206. [PubMed: 14757335]

39. Hanes KR. Neuropsychological performance in body dysmorphic disorder. J Int Neuropsychol Soc 1998;4:167-171. [PubMed: 9529826]

40. Carey P, Seedat S, Warwick J, van Heerden B, Stein DJ. SPECT imaging of body dysmorphic disorder. J Neuropsychiatry Clin Neurosci 2004;16:357-359. [PubMed: 15377744]

41. Grant JE, Kim SW, Crow SJ. Prevalence and clinical features of body dysmorphic disorder in adolescent and adult psychiatric inpatients. J Clin Psychiatry 2001;62:517-522. [PubMed: 11488361]

42. Phillips KA. The obsessive-compulsive spectrums. Psychiatr Clin N Am 2002;25:791-809.

43. Eisen JL, Phillips KA, Coles ME, Rasmussen SA. Insight in obsessive compulsive disorder and body dysmorphic disorder. Compr Psychiatry 2004;45:10-15. [PubMed: 14671731]

44. Grant JE, Phillips KA. Is anorexia nervosa a subtype of body dysmorphic disorder? Harv Rev Psychiatry 2004;12:1-4. [PubMed: 14965851]

45. Crisp AH, Hsu LKG, Harding B, Hartshorn J. Clinical features of anorexia nervosa. J Psychosom Res 1980;24:179-191. [PubMed: 7441586]

46. Phillips KA. Pharmacologic treatment of body dysmorphic disorder: Review of the evidence and a recommended treatment approach. CNS Spectr 2002;7:453-460. [PubMed: 15107767]

47. Weintraub E, Robinson C. A case of monosymptomatic hypochondriacal psychosis treated with olanzapine. Ann Clin Psychiatry 2000;12:247-249. [PubMed: 11140927]

48. Grant JE. Successful treatment of nondelusional body dysmorphic disorder with olanzapine: A case report. J Clin Psychiatry 2001;62:297-298. [PubMed: 11379848]

49. Neziroglu F, Khemlani-Patel S. A review of cognitive and behavioral treatment for body dysmorphic disorder. CNS Spectr 2002;7:464-471. [PubMed: 15107768]

50. Wilhelm S, Otto MW, Lohr B, Deckersbach T. Cognitive behavior group therapy for body dysmorphic disorder: A case series. Behav Res Ther 1999;37:71-75. [PubMed: 9922559]

51. McKay D. Two-year follow-up of behavioral treatment and maintenance for body dysmorphic disorder. Behav Modif 1999;23:620-629. [PubMed: 10533443]

52. Rosen JC, Reiter J, Orosan P. Cognitive-behavioral body image therapy for body dysmorphic disorder. J Consult Clin Psychol 1995;63:263-269. [PubMed: 7751487] 
53. Veale D, Gournay K, Dryden W, Boocock A, Shah F, Willson R, Walburn J. Body dysmorphic disorder: A cognitive behavioural model and pilot randomised controlled trial. Behav Res Ther 1996;34:717-729. [PubMed: 8936754]

54. Hollander E, Allen A, Kwon J, Aronowitz B, Schmeidler J, Wong C, Simeon D. Clomipramine vs desipramine crossover trial in body dysmorphic disorder: Selective efficacy of a serotonin reuptake inhibitor in imagined ugliness. Arch Gen Psychiatry 1999;56:1033-1039. [PubMed: 10565503]

55. Phillips KA, Albertini RS, Rasmussen SA. A randomized placebo-controlled trial of fluoxetine in body dysmorphic disorder. Arch Gen Psychiatry 2002;59:381-388. [PubMed: 11926939]

56. Phillips, Ka. Placebo-controlled study of pimozide augmentation of fluoxetine in body dysmorphic disorder. Am J Psychiatry 2005;162:377-379. [PubMed: 15677604]

57. Phillips KA, Dwight MM, McElroy SL. Efficacy and safety of fluvoxamine in body dysmorphic disorder. J Clin Psychiatry 1998;59:165-171. [PubMed: 9590666]

58. Perugi G, Giannotti D, Di Vaio S, Frare F, Saettoni M, Cassano GB. Fluvoxamine in the treatment of body dysmorphic disorder (dysmorphophobia). Int Clin Psychopharmacol 1996;11:247-254. [PubMed: 9031991]

59. Phillips KA, Najjar F. An open-label study of citalopram in body dysmorphic disorder. J Clin Psychiatry 2003;64:715-720. [PubMed: 12823088] 
Complications of BDD $(\mathrm{N}=434)$

\section{Table 1}

Social Impairment

Professional/Academic Impairment

Psychiatric Hospitalization

Housebound

Suicidal Ideation

Suicide Attempts

Unpublished data. 


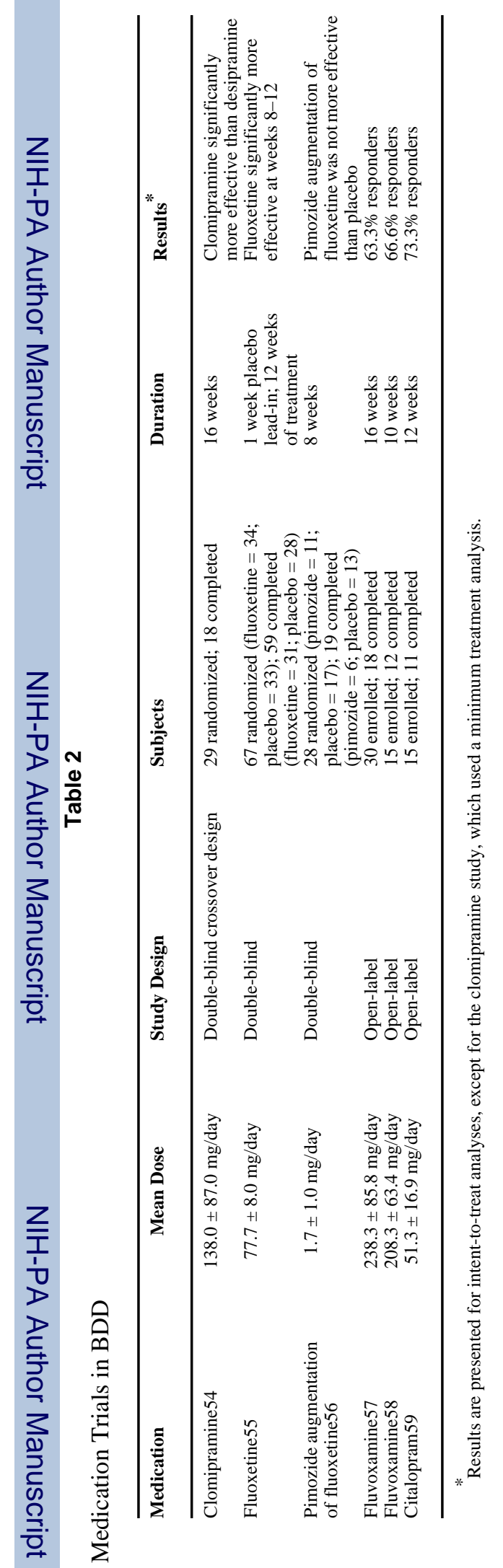

